\title{
Surgical Resection and Prognostic Analysis of 142 Cases of Hilar Cholangiocarcinoma
}

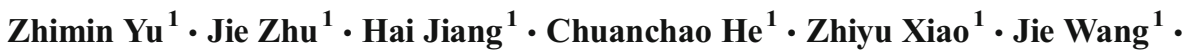 \\ Junyao $\mathrm{Xu}^{1}$
}

Received: 11 August 2016 / Accepted: 23 December 2016/Published online: 7 January 2017

(C) Association of Surgeons of India 2017

\begin{abstract}
Surgical resection for hilar cholangiocarcinoma is the only curative option, but low resectability rate and poor survival outcomes remain a challenge. This study was to assess the surgical resection for hilar cholangiocarcinoma and analyze the prognostic factors influencing postoperative survival. One hundred forty-two patients with hilar cholangiocarcinoma who underwent surgical resection between January 2006 and December 2014 were analyzed retrospectively based on clinicopathological and demographic data. Univariate and multivariate analysis against outcome were employed to identify potential factors affecting prognosis. Ninety-five patients were performed with R0 resection with median survival time of 22 months; whereas, 47 patients underwent non-R0 resection $(\mathrm{R} 1=20, \mathrm{R} 2=27)$ with that of 10 months. Of these 95 patients, 19 underwent concomitant with vascular resection and reconstruction and 2 patients underwent pancreaticoduodenectomy. $64.8 \%$ patients $(n=92)$ underwent combined with hepatectomy. The oneyear, three-year, and five-year survival rates after R0 resection were $76.3,27.8,11.3 \%$, respectively, which was significantly better than that after non-curative resection $(P=0.000)$. Multivariate analysis revealed that non-curative resection (RR: $2.414,95 \%$ CI $1.586-3.676, P=0.000$ ), pathological
\end{abstract}

Zhimin Yu and Jie Zhu are co-first authors and contributed equally to this work.

Jie Wang

sumsjw@163.com

$\checkmark$ Junyao Xu

xuyuny@mail.sysu.edu.cn

1 Guandong Provincial Key Laboratory of Malignant Tumor Epigenetics and Gene Regulation, Department of Hepatobiliary Surgery, Sun Yat-Sen Memorial Hospital, Sun Yat-Sen University, \#33 Yingfeng Road, Guangzhou 510120, People's Republic of China differentiation $(P=0.015)$ and preoperative serum total bilirubin above $10 \mathrm{mg} / \mathrm{dL}$ (RR: $1.844,95 \%$ CI $1.235-2.752$, $P=0.003$ ) were independent prognostic factors. Aggressive curative resection remains to be the optimal option for hilar cholangiocarcinoma. Non-curative resection, pathological differentiation, and preoperative serum total bilirubin above $10 \mathrm{mg} / \mathrm{dL}$ were associated with dismal prognosis.

Keywords Hilar cholangiocarcinoma · Curative resection . Hepatectomy $\cdot$ Survival $\cdot$ Prognostic factor

\section{Introduction}

Hilar cholangiocarcinoma (HCCA) comprising approximately $50 \%$ of all malignant bile duct tumors, is an intractable cancer [1], which requires a high level of expertise in hepatobiliary surgery due to the deep anatomical location of tumor $[2,3]$. In addition, curative resection for HCCA is a complex procedure involving hepatectomy, lymphadenectomy, vascular resection and reconstruction, even pancreaticoduodenectomy (PD) $[4,5]$. Consequently, curative resection is a challenging surgery and carries with a considerable risk of mortality and severe postoperative morbidity [6, 7]. Undoubtedly, curative resection offers HCCA patients the only potential chance for long-term survival, but the rates of mortality and morbidity require further improvement [8]. Meanwhile, many definitive prognostic factors affecting the postoperative survival have not been identified and accepted by surgeons [9-13], despite majority investigations have focused on this field. Therefore, the aims of this study were to assess the surgical management for HCCA and analyze potential factors influencing postoperative prognosis. 


\section{Materials and Methods}

\section{Patients}

Between January 2006 and December 2014, 216 patients with a presumed diagnosis of HCCA were admitted to the Department of Hepatobiliary, Sun-Yat-Sen Memorial Hospital, Sun-Yat-Sen University. With the approval of local institutional review board, we reviewed the medical records of all potential candidates for surgery. Seventy-four patients without any surgical interventions were excluded due to multiple metastasis, severe preoperative malnutrition, compromised liver function or severe involvement of contralateral major vessels. Therefore, curative-intent laparotomy was conducted in the remaining 142 patients. Consequently, 95 patients underwent curative resection (R0 resection) and 47 patients were performed with palliative resection $(\mathrm{R} 1=20$, $\mathrm{R} 2=27$ ). All the 142 patients were enrolled into this study.

\section{Preoperative Evaluation and Management}

To comprehensively evaluate disease lesion and assess surgical resectability, the laboratory and imaging examinations were carried out for all candidates. The lesion location, proximal and distal extension of tumor as well as vascular involvement extent were evaluated by ultrasonography, multidetector row computed tomography (MDCT), and magnetic resonance cholangiopancreatography (MRCP). Patients who were scheduled to accept major hepatectomy with preoperative serum total bilirubin over $11.70 \mathrm{mg} / \mathrm{dL}(200 \mu \mathrm{mol} / \mathrm{L})$ were suggested with biliary drainage prior to surgery. None of patients underwent portal vein embolization (PVE). Percutaneous transhepatic cholangial drainage (PTCD) under ultrasound guidance was performed for 33 patients and 4 patients underwent endoscopic nasobiliary drainage (ENBD). When the surgical approach of extended hepatectomy was established preoperatively, three dimensional computed tomography (3-D CT) volumetry was applied to calculate the remnant liver in order to avoid hepatic failure postoperatively. Definitive surgery arrangement was carried out when preoperative serum total bilirubin level decreased to below $11.70 \mathrm{mg} / \mathrm{dL}(200 \mu \mathrm{mol} / \mathrm{L})$, whereas those without biliary drainage were performed with surgery within 7 days.

\section{Surgical Procedures}

Surgical resections consisting of hemihepatectomy, extended hemihepatectomy, central hepatectomy, and external bile duct resection with or without caudate lobectomy were carried out on individuals referring to Bismuth-Corlette classification with imaging information. Locoregional lymphadenectomy including nodes at the hepatoduodenal ligament and upper part of the retropancreatic, and celiac nodes was routinely carried out. Upon the completion of the tumor resection, the biliary tract reconstruction was reestablished by Roux-en-Y bilioenteric anastomosis.

Vascular resection and reconstruction was carried out only when vessels adhered to and could not be freed from tumor entity during skeletonization of the hepatoduodenal ligament, regardless of whether the macrovascular invasion was detected preoperatively by MDCT [14]. Meanwhile, the end-to-end anastomosis model or vascular prothesis was employed to reestablish vascular continuity.

Pathologic verification was performed for all resected specimens. R0 resection was of microscopically tumor-free and a microscopically positive margin was defined as $\mathrm{R} 1$ resection. $\mathrm{R} 2$ resection meant grossly positive margins. According to the predominant pathologic grade of differentiation, tumor was mainly classified as three types: well-differentiated, moderately differentiated, and poorly differentiated adenocarcinoma. Apart from these, perineural invasion, lymph nodal metastasis, vascular invasion including hepatic artery, portal vein, and tumor thrombi were also assessed.

\section{Definition of Mortality and Morbidity}

Mortality was defined as any postoperative death occurring inhospital stay. Major complications were regarded as having a grade of III-IV according to Clavien-Dindo classification [15].

\section{Statistics}

Continuous variables were expressed as median and range. The category variables were expressed as numbers. Cumulative survival time counted from the month of surgery was calculated with the Kaplan-Meier method and difference in survival curves was compared through log-rank test. A Student's $t$ test (two-tailed) or Mann-Whitney $U$ tests and $\chi^{2}$ test or Fisher's exact test were used to analyze continuous or categorical variables, respectively. A multivariate Cox proportional hazards regression analysis (enter method) was performed to identify variables with $P$ values less than 0.05 in the univariate analysis. $P$ values less than 0.05 was considered to be significant. The statistical analyses were performed with SPSS 17.0.

\section{Results}

\section{Demographic and Clinicopathological Features of Patients}

The current study population consisted of 84 male and 58 female patients with a mean age of 59.5 years (range, 2882 years). According to Bismuth-Corlette classification, 16 
(11.27\%) patients were with type I, 15 (10.56\%) with type II, $17(11.97 \%)$ with type IIIA, $38(26.76 \%)$ with IIIB, and 56 (39.44\%) with IV. Clinicopathological and demographic features of these candidates showed no significant difference factors between these with $\mathrm{R} 0$ resection and those with noncurative resection, except for perineural invasion ( $P=0.000)$ (Table 1).

\section{Operative Variables}

In the whole cohort, 95 patients were performed with $\mathrm{R} 0$ resection, while the remaining 47 underwent non-curative resection including $\mathrm{R} 1$ resection $(n=20)$ and $\mathrm{R} 2$ resection $(n=27)$. A total of 92 patients $(92 / 142,64.8 \%)$ underwent combined with hepatectomy. Meanwhile, 34 out of these $92(37.0 \%)$ patients underwent caudate lobectomy. Consequently, the R0 resection rate of those who underwent combined with hepatectomy was 75\% (69/92). In addition, another 2 patients with type I lesion were conducted with PD. The details of surgical procedures of candidates who underwent surgery were depicted in Table 2.

Vascular resection and reconstruction was carried out in 19 patients including right hepatic artery alone $(n=6)$, portal bifurcation plus right hepatic artery $(n=3)$, and portal bifurcation alone $(n=10)$. The portal vein reconstruction was by model of end-to-end anastomosis $(n=12)$ and vascular prothesis $(n=1)$ between the residual trunk and corresponding branch, and the hepatic arterial reconstruction were based on fashion of end-to-end ( $n=4)$ or with gastroduodenal artery anastomosis $(n=2)$.

\section{Postoperative Hospital Stay and Survival}

The median postoperative hospital stay was 23 days (range 13-119 days) with curative resection and 14 days (8-105 days) with non-curative resection. The cumulative overall 1-year, 3year, and 5-year survival rates were $76.3,27.8$, and $11.3 \%$, respectively, in curative resection group vs $36.4,10.8$, and $0 \%$ in non-resection group $(P=0.000)$. Median survival time after curative resection was 22 and 10 months after non-curative resection.

\section{Mortality and Morbidity}

The perioperative overall mortality rate in this study was $7.0 \%$ (10/142). Mortality occurred to 10 patients consisting of 4 in curative resection group and 6 in non-curative resection group. The main causes of mortality included hepatic failure resulting in multiple organ failure $(n=6)$, pneumonia causing respiratory failure $(n=2)$, postoperative gastrointestinal hemorrhage $(n=1)$, and anastomosis site leakage $(n=1)$. A total of 83 patients suffered from postoperative complications with the overall morbidity rate of $58.5 \%$. Meanwhile, $27.5 \%$ patients
(39/83) encountered major complications (grade III to IV). Bile leakage was the most frequent complication and observed in 38 patients. Relaparotomy was required in 6 patients due to intra-abdominal bleeding $(n=4)$ and bilioenteric anastomosis bleeding $(n=2)$ within 7 days postoperatively. The details of postoperative complications were summarized in Table 3.

\section{Statistic Analysis}

Univariate analysis suggested CA19-9, preoperative serum total bilirubin, marginal status, pathological differentiation, and lymph nodes status were significant predictors for poor survival (Table 4). Meanwhile, Cox multivariate analysis disclosed that non-curative resection (RR: $2.414,95 \% \mathrm{CI}$ 1.586-3. 676, $P=0.000)$, pathological differentiation $(P=0.015)$, serum total bilirubin $\geq 10 \mathrm{mg} / \mathrm{dL}$ (RR: 1.844 , 95\% CI 1.235-2.752, $P=0.003$ ) were independent prognostic factors (Fig. 1).

\section{Discussion}

Surgical resection has been recognized as an only potential curative option for HCCA $[1,2]$. Despite close proximity to hilum vital structures and longitudinal extension of HCCA make curative resection a challenge, an improvement in postoperative survival has been reported with the advances of surgical techniques. The recent literature reviews of highvolume center of HCCA treated surgically indicate the median survival time is 16-40 months with 5-year survival rate of 11$40 \%$, and perioperative mortality rate is around $10 \%$ with morbidity rate of approximate 42-75\% [2, 4, 9, 13, 16, 17]. In the present study, combined hepatectomy including caudate lobectomy was conducted in $64.8 \%$ patients $(92 / 142)$, and $13.39 \%$ patients $(19 / 142)$ underwent concomitant vascular resection and reconstruction. Besides that, it was noted that $66.20 \%$ patients $(94 / 142)$ who underwent surgical resection were with type III (IIIA or IIIB) or type IV lesion. Consequently, the one-year, three-year, and five-year survival rates in curative resection group were $76.3,27.8$, and $11.3 \%$, respectively, and overall morbidity rate was $58.3 \%$ with perioperative mortality of $7.0 \%$. Despite our results was not enough favorable but acceptable, at least, which was compatible with that reported in previous published series.

It is an incontrovertible fact combined hepatectomy or extended hepatectomy have markedly increased the resectable rate of HCCA $[6,18,19]$. It has been increased from traditionally $30 \%$ to currently $49.2-95 \%$ [2, 9, 13$]$. Simultaneously, the median survival of HCCA has also been dramatically ameliorated. KY. Paik et al. [20] reported 5-year survival rate was $64.2 \%$ without any in-hospital death of 16 patients who underwent right trisectionectomy with caudate lobectomy. In the study of Shimizu et al. [21], the R0 rate was 
Table 1 Demographic and clinicopathological features of 142 HCCA patients

\begin{tabular}{|c|c|c|c|}
\hline & Curative resection group & Palliative resection group (R1/R2) & $P$ value \\
\hline Number of patients & 95 & 47 & \\
\hline Age & $59.92(28-82)$ & $59.11(32-76)$ & 0.681 \\
\hline Gender & $\mathrm{M}=57, \mathrm{~F}=38$ & $M=27, F=20$ & 0.771 \\
\hline Mean serum total bilirubin & $219.05(5.7-712.7)$ & $207.9(9.6-647.5)$ & 0.504 \\
\hline CEA & $6.87(0.4-202.9)$ & $16.3(0.5-352.9)$ & 0.176 \\
\hline CA19-9 & $2376.3(0-100,000)$ & $5820.5(0-100,000)$ & 0.228 \\
\hline ALB & $37.95(17.9-47.2)$ & $37.78(28.2-45.8)$ & 0.531 \\
\hline PTCD & 26 & 11 & 0.688 \\
\hline Bismuth-Corlette classification: & & 0.122 & \\
\hline I & 9 & 7 & \\
\hline II & 8 & 7 & \\
\hline IIIA & 9 & 8 & \\
\hline IIIB & 31 & 7 & \\
\hline IV & 38 & 18 & \\
\hline Pathological differentiation: & & & 0.500 \\
\hline Well & 33 & 16 & \\
\hline Moderate & 34 & 13 & \\
\hline Poor & 28 & 18 & \\
\hline Perineural invasion & 51 & 10 & 0.000 \\
\hline Lymph nodes metastases & 47 & 22 & 0.765 \\
\hline Hepatitis virus infection & 12 & 4 & 0.465 \\
\hline No.12 lymph nodes invasion ${ }^{\mathrm{a}}$ & 39 & 16 & 0.420 \\
\hline Tumor thrombi & 19 & 4 & 0.080 \\
\hline
\end{tabular}

${ }^{\mathrm{a}}$ Lymph nodes at hepatoduodenal ligament
Table 2 Sugical procedures of 142 HCCA patients

\begin{tabular}{llllll}
\hline Bismuth-Corlette classification: & I & II & IIIA & IIIB & IV \\
\hline Numbers & 16 & 15 & 17 & 38 & 56 \\
Margin status: & & & & & \\
R0 & 9 & 8 & 9 & 31 & 38 \\
R1 & 3 & 4 & 6 & 1 & 6 \\
R2 & 4 & 3 & 2 & 6 & 12 \\
Surgical procedures: & & & & & \\
External bile duct resection & 12 & 13 & 3 & 5 & 9 \\
External bile duct resection with S4b & 2 & 1 & 2 & 2 & 2 \\
Right hemihepatectomy & 0 & 0 & 9 & 0 & 13 \\
Right hemihepatectomy with S1 & 0 & 0 & 1 & 0 & 0 \\
Extended right hemihepatectomy & 0 & 0 & 2 & 0 & 5 \\
Extended right hemihepatectomy with S1 & 0 & 0 & 0 & 0 & 4 \\
Left hemihepatectomy & 0 & 0 & 0 & 11 & 9 \\
Left hemihepatectomy with S1 & 0 & 1 & 0 & 15 & 7 \\
Extended left hemihepatectomy with S1 & 0 & 0 & 0 & 3 & 3 \\
Central hepatectomy & 0 & 0 & 0 & 2 & 4 \\
Pancreaticoduodenectomy & 2 & 0 & 0 & 0 & 0 \\
\hline
\end{tabular}

$63.6 \%$ for patients who underwent left-side hepatectomy and 5 -year survival was $36.7 \%$ with median survival of 24.4 months. In addition, patients with type IV lesion were previously considered not suitable for surgery, which was documented by the American Joint Committee on Cancer (AJCC) cancer staging manual (7th, edition). However, a study of combined extended hepatectomy for those who with type IV from Jang et al. [22] indicated that median survival time was 16 months in curative resection group and 12 months in palliative resection group $(P=0.006)$. Consistent with the previous literatures, $\mathrm{R} 0$ resection rate of those who underwent combined with hepatectomy was 75\% (69/92) in this series, which was higher than the overall curative resection rate of $66.9 \%$ (95/142). Furthermore, 67.86\% (38/56) patients with type IV underwent curative resection with median survival time of 23 months, which was significantly better than that of 7 months with non-curative resection $(P=0.000)$. Although combined hepatectomy did not develop impacts on postoperative survival in our study $(P=0.302)$, we believed that combined hepatectomy was essential to obtain higher $\mathrm{R} 0$ resection rate and benefit selected HCCA patients.

For another, combined with vascular resection and reconstruction has also made contribution to improvement resectability of HCCA currently, though it was regarded as a 
Table 3 Postoperative complications of 142 HCCA patients

$\begin{array}{lll}\text { No. of patients with } & \text { No. of patients } & \text { Total } \\ \text { curative resection } & \text { with palliative } & n=142 \\ n=95 & \text { resection } n=47 & \end{array}$

Morbidity $^{\mathrm{a}}$

Grade IVa

Hepatic encephalop-

athy

Hepatic or 4

renal

insufficien-

cy

ARDS

2

Grade IIIb

Intra-abdo-

0

minal

abscess

Liver abscess $\quad 0$

Bilioenteric 2

anastomosis

bleeding

Intra-abdo-

minal

bleeding

Grade IIIa

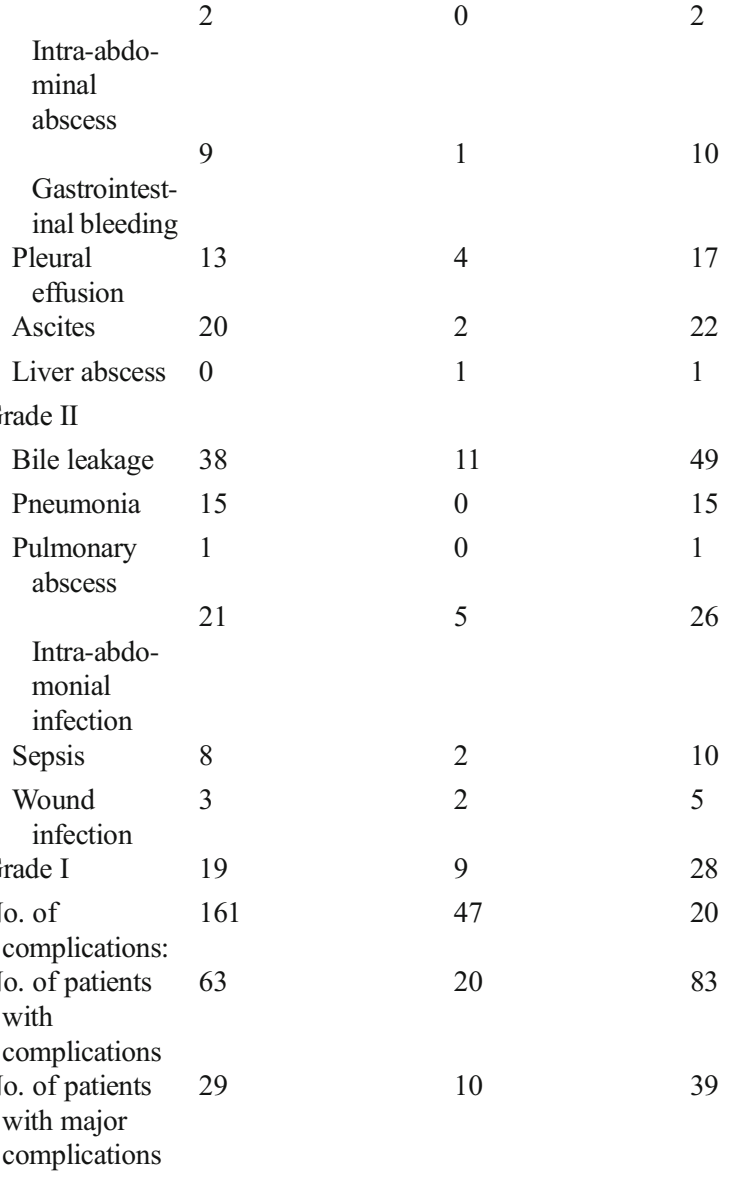

Table 3 (continued)

\begin{tabular}{llll}
\hline & $\begin{array}{l}\text { No. of patients with } \\
\text { curative resection } \\
n=95\end{array}$ & $\begin{array}{l}\text { No. of patients } \\
\text { with palliative } \\
\text { resection } n=47\end{array}$ & $\begin{array}{l}\text { Total } \\
n=142\end{array}$ \\
\hline $\begin{array}{l}\text { Postoperative } \\
\text { hospital stays } \\
\text { (day) }\end{array}$ & 23 & 14 & \\
\hline
\end{tabular}

${ }^{a}$ According to Clavein-Dindo classification

common surgical contraindication previously [23, 24]. The 5 year survival rate of combined with portal vein resection and reconstruction for HCCA in series of over 10 cases reported ranges from $9.9 \%$ to $25 \%$ with mortality of $9.6 \%-40 \%$ $[25,26]$. In the current series, the median survival time for 19 patients who underwent combined with vascular resection and reconstruction was 17 months with one-year, three-year survival rates of $78.8 \%, 21.3 \%$ respectively. And the mortality was $5.26 \%(1 / 19)$. Although these outcomes was inferior to results in recent literatures, compared with median survival of advanced cholangiocarcinoma without any interventional procedures, combined with vascular resection and reconstruction offered advanced HCCA patients chance for acceptable survival benefits to some extent $[27,28]$.

As we all know, postoperative liver failure is the fatal complication of aggressive hepatic surgery, which makes the significance of preoperative biliary drainage under controversial debate to certain extent. Although zero mortality rate after R0 resection for HCCA has been achieved by Sano et al. with preoperative biliary drainage routinely applied [13], multivariate analysis of their study also revealed preoperative cholangitis was associated with postoperative mortality and morbidity. In this study, patients who were scheduled to undergo major hepatectomy with preoperative serum total bilirubin over $11.70 \mathrm{mg} / \mathrm{dL}(200 \mu \mathrm{mol} / \mathrm{L})$ were suggested with biliary drainage prior to surgery. Consequently, patients with preoperative serum total bilirubin below $10 \mathrm{mg} / \mathrm{dL}$ obtained apparent survival benefits than those with that above $10 \mathrm{mg} / \mathrm{dL}$ (20 vs 14 months, $P=0.003$ ). Additionally, preoperative biliary drainage trends to result in bile duct infections, even delay treatment [29]. Therefore, to obtain the better outcomes of surgery, preoperative biliary drainage should be a selective procedure which is depended on preoperative definitive serum total bilirubin level and scheduled surgical policy.

Although many investigations published have established various clinicopathologic factors focusing on affecting prognosis of HCCA [9-13, 23], the most consistently reported and well-recognized independently determinant factors is surgical margin status. Hepatitis and tumor thrombi regarded as potential prognostic factors were seldom discussed. To our knowledge, only a few studies have described the role of hepatitis 
Table 4 Univariate and multivariate analysis of prognostic factors of survival outcome of 142 HCCA patients

\begin{tabular}{|c|c|c|c|c|c|c|}
\hline \multirow[t]{2}{*}{ Factors } & \multirow{2}{*}{$\begin{array}{l}\text { No.of } \\
\text { patients }\end{array}$} & \multicolumn{3}{|c|}{ Univariate analysis } & \multicolumn{2}{|c|}{ Multivariate analysis } \\
\hline & & $\begin{array}{l}\text { Median survival } \\
\text { (month) }\end{array}$ & $\begin{array}{l}\chi^{2} \\
\text { value }\end{array}$ & $\begin{array}{l}P \\
\text { value }\end{array}$ & $\mathrm{RR}(95 \% \mathrm{CI})$ & $\begin{array}{l}P \\
\text { value }\end{array}$ \\
\hline Age & & & 0.975 & 0.332 & & \\
\hline$<60$ & 72 & 20 & & & & \\
\hline$\geq 60$ & 70 & 15 & & & & \\
\hline Agender & & & 0.521 & 0.471 & & \\
\hline Male & 84 & 17 & & & & \\
\hline Female & 58 & 14 & & & & \\
\hline TBIL & & & 5.436 & 0.020 & & 0.003 \\
\hline$<10 \mathrm{mg} / \mathrm{dL}$ & 79 & 20 & & & Reference & \\
\hline$\geq 10 \mathrm{mg} / \mathrm{dL}$ & 63 & 14 & & & $\begin{array}{l}1.844,95 \% \text { CI } \\
\quad(1.235-2.752)\end{array}$ & \\
\hline CEA level & & & 3.634 & 0.057 & & \\
\hline$<15 \mathrm{ng} / \mathrm{ml}$ & 134 & 17 & & & & \\
\hline$\geq 15 \mathrm{ng} / \mathrm{ml}$ & 8 & 8 & & & & \\
\hline CA-199 level & & & 4.748 & 0.029 & & 0.459 \\
\hline$<200 \mathrm{U} / \mathrm{ml}$ & 67 & 20 & & & Reference & \\
\hline$\geq 200 \mathrm{U} / \mathrm{ml}$ & 75 & 13 & & & $\begin{array}{l}1.174,95 \% \text { CI } \\
(0.768-1.793)\end{array}$ & \\
\hline ALB level & & & 0.292 & 0.589 & & \\
\hline$<35 \mathrm{~g} / \mathrm{L}$ & 25 & 18 & & & & \\
\hline$\geq 35 \mathrm{~g} / \mathrm{L}$ & 117 & 16 & & & & \\
\hline PTCD & & & 0.763 & 0.382 & & \\
\hline Present & 37 & 14 & & & & \\
\hline Absent & 105 & 17 & & & & \\
\hline $\begin{array}{l}\text { Bismuth-Corlette } \\
\text { classification }\end{array}$ & & & 2.993 & 0.559 & & \\
\hline I & 16 & 20 & & & & \\
\hline II & 15 & 12 & & & & \\
\hline IIIA & 17 & 15 & & & & \\
\hline IIIB & 38 & 17 & & & & \\
\hline IV & 56 & 18 & & & & \\
\hline Hepatitis virus infection & & & 0.398 & 0.528 & & \\
\hline Present & 16 & 16 & & & & \\
\hline absent & 126 & 20 & & & & \\
\hline Resection margin & & & 21.858 & 0.000 & & 0.000 \\
\hline R0 & 95 & 22 & & & Reference & \\
\hline $\mathrm{R} 1 / \mathrm{R} 2$ & 47 & 10 & & & $\begin{array}{l}2.268,95 \% \text { CI } \\
\quad(1.493-3.444)\end{array}$ & \\
\hline $\begin{array}{l}\text { Combined } \\
\text { hepatectomy }\end{array}$ & & & 0.302 & 0.583 & & \\
\hline Yes & 92 & 17 & & & & \\
\hline No & 50 & 16 & & & & \\
\hline $\begin{array}{l}\text { Combined caudate } \\
\text { lobectomy }\end{array}$ & & & 1.121 & 0.271 & & \\
\hline Present & 34 & 22 & & & & \\
\hline Absent & 108 & 15 & & & & \\
\hline $\begin{array}{l}\text { Combined vascular } \\
\text { reconstruction }\end{array}$ & & & 0.123 & 0.726 & & \\
\hline Present & 19 & 17 & & & & \\
\hline Absent & 123 & 16 & & & & \\
\hline
\end{tabular}


Table 4 (continued)

\begin{tabular}{|c|c|c|c|c|c|c|}
\hline \multirow[t]{2}{*}{ Factors } & \multirow{2}{*}{$\begin{array}{l}\text { No.of } \\
\text { patients }\end{array}$} & \multicolumn{3}{|c|}{ Univariate analysis } & \multicolumn{2}{|c|}{ Multivariate analysis } \\
\hline & & $\begin{array}{l}\text { Median survival } \\
\text { (month) }\end{array}$ & $\begin{array}{l}\chi^{2} \\
\text { value }\end{array}$ & $\begin{array}{l}P \\
\text { value }\end{array}$ & $\mathrm{RR}(95 \% \mathrm{CI})$ & $\begin{array}{l}P \\
\text { value }\end{array}$ \\
\hline $\begin{array}{l}\text { Postoperative } \\
\text { chemotherapy }\end{array}$ & & & 1.331 & 0.249 & & \\
\hline Yes & 54 & 20 & & & & \\
\hline No & 88 & 14 & & & & \\
\hline $\begin{array}{l}\text { Pathologic } \\
\text { differentiation }\end{array}$ & & & 11.301 & 0.004 & & 0.015 \\
\hline Well & 49 & 24 & & & Reference & \\
\hline Moderate & 47 & 14 & & & $\begin{array}{l}1.139,95 \% \text { CI } \\
\quad(0.785-2.217)\end{array}$ & \\
\hline Poor & 46 & 12 & & & $\begin{array}{l}2.405,95 \% \text { CI } \\
\quad(1.250-3.345)\end{array}$ & \\
\hline Perineural invasion & & & 1.187 & 0.276 & & \\
\hline Present & 63 & 18 & & & & \\
\hline Absent & 79 & 15 & & & & \\
\hline Tumor thrombi & & & 0.776 & 0.378 & & \\
\hline Present & 19 & 16 & & & & \\
\hline Absent & 123 & 17 & & & & \\
\hline Lymph node metastases & & & 4.501 & 0.034 & & 0.247 \\
\hline Present & 69 & 20 & & & $\begin{array}{l}1.280,95 \% \text { CI } \\
(0.843-1.945)\end{array}$ & \\
\hline Absent & 73 & 15 & & & Reference & \\
\hline $\begin{array}{l}\text { No.12 lymph node } \\
\text { invasion }\end{array}$ & & & 3.578 & 0.059 & & \\
\hline Present & 90 & 17 & & & & \\
\hline Absent & 52 & 14 & & & & \\
\hline
\end{tabular}

virus infection for HCCA. In the study of Abdel Wahab M et al. [30], the median survival of patients with HCV infection was shorter than that of non-hepatitis virus infection patients $(P=0.005)$ and multivariate analysis confirmed that it was an independent prognostic factor. On the contrary, we failed to note that viral infection such as $\mathrm{HBV}$ or $\mathrm{HCV}$ has negative effect on postoperative prognosis of HCCA (16 vs 20 months, $P=0.528)$. Perhaps, the low morbidity of hepatitis (16/142) in this study was accounted for this discrepancy. Of course, the significance of hepatitis viral infection has remained uncertain
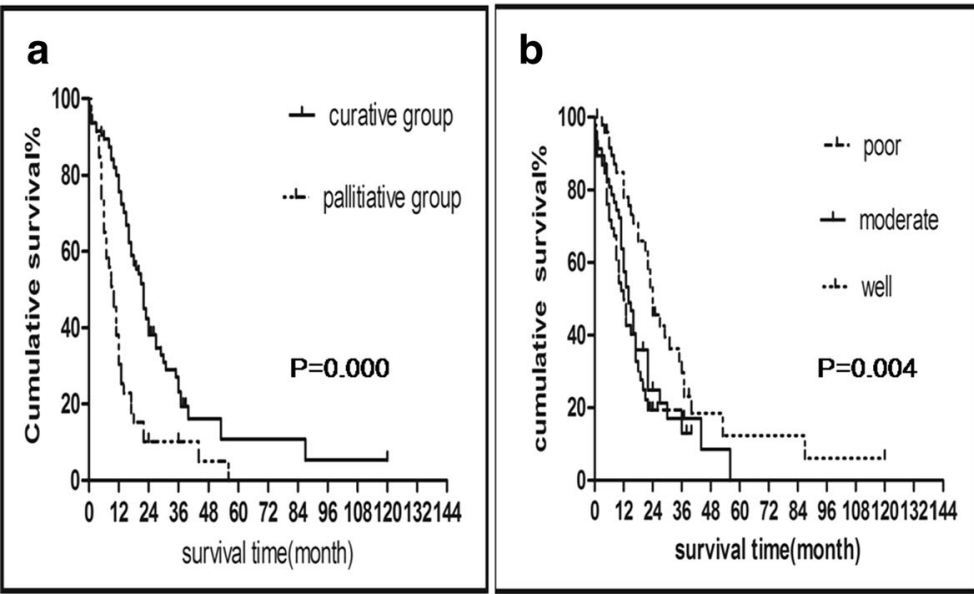

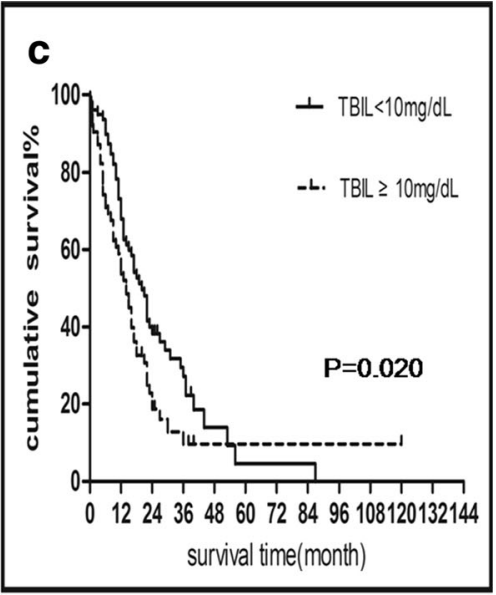

$P=0.000$ ), preoperative serum total bilirubin above $10 \mathrm{mg} / \mathrm{dL}$ (RR: $1.844,95 \%$ CI $1.235-2.752, P=0.003$ ) and pathological differentiation $(P=0.015)$ were independent prognostic risk factors for poor survival
Fig. 1 Overall survival rates according to the status of resection margin $(P=0.000)$, preoperative serum total bilirubin level $(P=0.020)$, and pathological differentiations $(P=0.004)$. Cox multivariate analysis revealed that non-curative resection (RR: $2.414,95 \%$ CI 1.586-3.676, 
and should be further explored. As for tumor thrombi, few reports concerned can be traced in recent literatures. In this study, the pathological examination revealed 19 patients with tumor thrombi invasion. As a result, the median survival time with pathological tumor thrombi invasion was 16 months, comparing with 17 months in absence of tumor thrombi invasion $(P=0.378)$. With the limitation of small sample, we could not confirm that whether the poor survival was associated with tumor thrombi invasion. Even so, tumor thrombi as an interesting factor deserves further exploration.

There are some limitations in this retrospective study. First, our relatively small study cohort resulting in influencing factors was not perceived as statistically reasonable or convincing. Second, in light of the retrospective nature of most published series including the current one, more valid data about surgical approach for HCCA should be provided by the future multicenter prospective studies. Last but not the least, the significance of postoperative adjuvant chemotherapy remains to be elaborated by randomized controlled trials, though our study did not demonstrate effects of adjuvant chemotherapy due to the small sample.

In summary, curative resection as a single curative therapy has benefited HCCA patients with acceptable mortality and morbidity. Combined hepatectomy with vascular resection and reconstruction have improved the resectability rate and survival outcomes. The further refinements of aggressive surgical techniques and improvement of therapeutic strategy would benefit more advanced HCCA patients.

Acknowledgements This work was supported by Grant 15ykpy20 from the young stuff foundation of Sun Yat-Sen University; Grant [2013] 163 from Key Laboratory of Malignant Tumor Mechanism and Translational Medicine of Guangzhou Bureau of Science and Information Technology; Grant KLB 09001 from the Key Laboratory of Malignant Tumor Gene Regulation and Target Therapy of Guangdong Higher Education Institutes.

\section{Compliance with Ethical Standards}

Conflict of Interest The authors declare that they have no conflict of interest.

Ethical Approval All procedures performed in studies involving human participants were in accordance with the ethical standards of the institutional and/or national research committee and with the 1964 Helsinki declaration and its later amendments or comparable ethical standards.

Informed Consent Informed consent was obtained from individual participants included in the study.

\section{Reference}

1. Khan SA, Davidson BR, Goldin RD, Heaton N, Karani J, Pereira SP, Rosenberg WM, Tait P, Taylor-Robinson SD,
Thillainayagam AV, Thomas HC, Wasan H, British Society of $\mathrm{G}$ (2012) Guidelines for the diagnosis and treatment of cholangiocarcinoma: an update. Gut 61(12):1657-1669. doi:10.1136/gutjnl-2011-301748

2. Ito F, Cho CS, Rikkers LF, Weber SM (2009) Hilar cholangiocarcinoma: current management. Ann Surg 250(2):210-218. doi:10.1097/SLA.0b013e3181afe0ab

3. Van Gulik TM, Gouma DJ (2007) Changing perspectives in the assessment of resectability of hilar cholangiocarcinoma. Ann Surg Oncol 14(7):1969-1971. doi:10.1245/s10434-007-9394-8

4. Kawasaki S, Imamura H, Kobayashi A, Noike T, Miwa S, Miyagawa S (2003) Results of surgical resection for patients with hilar bile duct cancer: application of extended hepatectomy after biliary drainage and hemihepatic portal vein embolization. Ann Surg 238(1):84-92. doi:10.1097/01. SLA.0000074984.83031.02

5. Nimura Y, Hayakawa N, Kamiya J, Maeda S, Kondo S, Yasui A, Shionoya S (1991) Hepatopancreatoduodenectomy for advanced carcinoma of the biliary tract. Hepato-Gastroenterology 38(2): $170-175$

6. Neuhaus P, Jonas S, Bechstein WO, Lohmann R, Radke C, Kling N, Wex C, Lobeck H, Hintze R (1999) Extended resections for hilar cholangiocarcinoma. Ann Surg 230(6): 808-818 discussion 819

7. Launois B, Terblanche J, Lakehal M, Catheline JM, Bardaxoglou E, Landen S, Campion JP, Sutherland F, Meunier B (1999) Proximal bile duct cancer: high resectability rate and 5-year survival. Ann Surg 230(2):266-275

8. Khan SA, Taylor-Robinson SD, Toledano MB, Beck A, Elliott P, Thomas HC (2002) Changing international trends in mortality rates for liver, biliary and pancreatic tumours. J Hepatol 37(6):806-813

9. DeOliveira ML, Cunningham SC, Cameron JL, Kamangar F, Winter JM, Lillemoe KD, Choti MA, Yeo CJ, Schulick RD (2007) Cholangiocarcinoma: thirty-one-year experience with 564 patients at a single institution. Ann Surg 245(5):755-762. doi:10.1097/01.sla.0000251366.62632.d3

10. Dumitrascu T, Chirita D, Ionescu M, Popescu I (2013) Resection for hilar cholangiocarcinoma: analysis of prognostic factors and the impact of systemic inflammation on long-term outcome. Journal of gastrointestinal surgery : official journal of the Society for Surgery of the Alimentary Tract 17(5):913-924. doi:10.1007/s11605-0132144-2

11. Song SC, Choi DW, Kow AW, Choi SH, Heo JS, Kim WS, Kim MJ (2013) Surgical outcomes of 230 resected hilar cholangiocarcinoma in a single centre. ANZ J Surg 83(4): 268-274. doi:10.1111/j.1445-2197.2012.06195.x

12. Furusawa N, Kobayashi A, Yokoyama T, Shimizu A, Motoyama H, Miyagawa S (2014) Surgical treatment of 144 cases of hilar cholangiocarcinoma without liver-related mortality. World J Surg 38(5): 1164-1176. doi:10.1007/s00268-013-2394-x

13. Sano T, Shimada K, Sakamoto Y, Yamamoto J, Yamasaki S, Kosuge T (2006) One hundred two consecutive hepatobiliary resections for perihilar cholangiocarcinoma with zero mortality. Ann Surg 244(2):240-247. doi:10.1097/01.sla.0000217605.66519.38

14. Serrablo A, Tejedor L (2013) Outcome of surgical resection in Klatskin tumors. World journal of gastrointestinal oncology 5(7): 147-158. doi:10.4251/wjgo.v5.i7.147

15. Dindo D, Demartines N, Clavien P-A (2004) Classification of surgical complications. Ann Surg 240(2):205-213. doi:10.1097/01. sla.0000133083.54934.ae

16. Hemming AW, Reed AI, Fujita S, Foley DP, Howard RJ (2005) Surgical management of hilar cholangiocarcinoma. Ann Surg 241(5):693-699 discussion 699-702

17. Jarnagin WR, Fong Y, DeMatteo RP, Gonen M, Burke EC, Bodniewicz BJ, Youssef BM, Klimstra D, Blumgart LH (2001) 
Staging, resectability, and outcome in 225 patients with hilar cholangiocarcinoma. Ann Surg 234(4):507-517 discussion 517-509

18. Kosuge T, Yamamoto J, Shimada K, Yamasaki S, Makuuchi M (1999) Improved surgical results for hilar cholangiocarcinoma with procedures including major hepatic resection. Ann Surg 230(5): $663-671$

19. Saxena A, Chua TC, Chu FC, Morris DL (2011) Improved outcomes after aggressive surgical resection of hilar cholangiocarcinoma: a critical analysis of recurrence and survival. Am J Surg 202(3): 310-320. doi:10.1016/j.amjsurg.2010.08.041

20. Paik KY, Choi DW, Chung JC, Kang KT, Kim SB (2008) Improved survival following right trisectionectomy with caudate lobectomy without operative mortality: surgical treatment for hilar cholangiocarcinoma. Journal of gastrointestinal surgery : official journal of the Society for Surgery of the Alimentary Tract 12:1268-1274. doi:10.1007/s11605-008-0503-1

21. Hiroaki Shimizu M, Fumio Kimura MD, Hiroyuki Yoshidome MD, Masayuki Ohtsuka MD, Atsushi Kato MD, Hideyuki Yoshitomi MD, Katsunori Furukawa MD, Masaru Miyazaki MD (2010) Aggressive surgical resection for hilar cholangiocarcinoma of the left-side predominance radicality and safety of left-sided hepatectomy. Ann Surg 251(2):281-286. doi:10.1097/SLA.0b013e3181 be 0085

22. Han IW, Jang JY, Kang MJ, Kwon W, Park JW, Chang YR, Kim SW (2014) Role of resection for Bismuth type IV hilar cholangiocarcinoma and analysis of determining factors for curative resection. Annals of surgical treatment and research 87(2):87-93. doi:10.4174/astr.2014.87.2.87

23. Zhang B-Y, Lu Y, Dong Q, Sun C-D, Mu P (2010) Surgical treatment and prognostic analysis of 93 cases of hilar cholangiocarcinoma. Am J Med Sci 339(3):221-224
24. de Groen PC, Gores GJ, LaRusso NF, Gunderson LL, Nagorney DM (1999) Biliary tract cancers. N Engl J Med 341(18):13681378. doi:10.1056/NEJM199910283411807

25. Ebata T, Nagino M, Kamiya J, Uesaka K, Nagasaka T, Nimura Y (2003) Hepatectomy with portal vein resection for hilar cholangiocarcinoma: audit of 52 consecutive cases. Ann Surg 238(5):720 727. doi:10.1097/01.sla.0000094437.68038.a3

26. Miyazaki M, Kato A, Ito H, Kimura F, Shimizu H, Ohtsuka M, Yoshidome H, Yoshitomi H, Furukawa K, Nozawa S (2007) Combined vascular resection in operative resection for hilar cholangiocarcinoma: does it work or not? Surgery 141(5):581-588. doi:10.1016/j.surg.2006.09.016

27. Park J, Kim MH, Kim KP, Park do H, Moon SH, Song TJ, Eum J, Lee SS, Seo DW, Lee SK (2009) Natural history and prognostic factors of advanced cholangiocarcinoma without surgery, chemotherapy, or radiotherapy: a large-scale observational study. Gut and liver 3(4):298-305. doi:10.5009/gnl.2009.3.4.298

28. Farley DR, Weaver AL, Nagorney DM (1995) "Natural history" of unresected cholangiocarcinoma: patient outcome after noncurative intervention. Mayo Clin Proc 70(5):425-429. doi:10.1016/S00256196(11)63877-9

29. Arakura N, Takayama M, Ozaki Y, Maruyama M, Chou Y, Kodama R, Ochi Y, Hamano H, Nakata T, Kajikawa S, Tanaka E, Kawa S (2009) Efficacy of preoperative endoscopic nasobiliary drainage for hilar cholangiocarcinoma. J Hepato-Biliary-Pancreat Surg 16(4): 473-477. doi:10.1007/s00534-009-0076-8

30. Abdel Wahab M, Fathy O, Elghwalby N, Sultan A, Elebidy E, Abdalla T, Elshobary M, Mostafa M, Foad A, Kandeel T, Abdel Raouf A, Salah T, Abu Zeid M, Abu Elenein A, Gad Elhak N, ElFiky A, Ezzat F (2006) Resectability and prognostic factors after resection of hilar cholangiocarcinoma. Hepato-Gastroenterology 53(67):5-10 